Case Report

DOI: https://dx.doi.org/10.18203/issn.2454-5929.ijohns20212905

\title{
Middle ear squamous cell carcinoma: a case report
}

\section{Nilesh H. Mahajan*, Asha M., Vinaykumar Vijayendra, Vijayendra Honnurappa}

Vijaya E.N.T. Care Centre, Superspeciality Otology Centre, Bangalore, Karnataka, India

Received: 11 May 2021

Revised: 01 July 2021

Accepted: 02 July 2021

\section{*Correspondence:}

Dr. Nilesh H. Mahajan,

E-mail: nilesh.virtual@gmail.com

Copyright: (c) the author(s), publisher and licensee Medip Academy. This is an open-access article distributed under the terms of the Creative Commons Attribution Non-Commercial License, which permits unrestricted non-commercial use, distribution, and reproduction in any medium, provided the original work is properly cited.

\begin{abstract}
Squamous cell carcinoma of middle ear is a rare entity. We present a case of 77 year old male, with squamous cell carcinoma of middle ear. Patient presented with blood tinged otorrhoea. Oto-endoscopy examination revealed a soft tissue lesion in middle ear which bled on touch. Histopathological study of this soft tissue lesion gave a diagnosis of well differentiated squamous cell carcinoma. Radical clearance of the tumour achieved after removal of the malleus and incus. Tumour was seen extending into the eustachian tube orifice and it was removed in toto. Uderlying bone was ablated using diode laser to confirm the radical clearance. Later patient was given radiotherapy 6 weeks after surgery to allow the healing of the operative site. The objective to report this case was to emphasize the importance of early diagnosis and prompt treatment for a better survival. Long standing history of ear discharge with soft tissue lesion bleeding on touch should always be evaluated by histopathological study to exclude malignancy.
\end{abstract}

Keywords: Middle ear, Squamous cell carcinoma, Chronic suppurative otitis media

\section{INTRODUCTION}

Middle ear cancer represents 5-10\% of all ear neoplasms. Squamous cell carcinoma (SCC) constitutes majority of these neoplasms. ${ }^{1} \mathrm{SCC}$ arising from chronic suppurative otitis media (CSOM) is a rare complication with the reported incidence being $1 / 4000$ cases.

Early manifestations of SCCME are similar to CSOM, rendering early diagnosis difficult. Because of the low incidence and infrequent reports of SCCME, the extent of concordance between computed tomography (CT) and magnetic resonance imaging (MRI) results, surgical findings, and pathology reports are not wellcharacterized. $^{2}$

It is important to detect these lesions very early, since they retain a poor prognosis despite the development of increasingly radical surgical procedures and advances in radiotherapy. ${ }^{4}$ Herein, we report one such rare case of SCC arising in a background of CSOM.

\section{CASE REPORT}

A 77-year-old male presented with one month history of exacerbated discharge from the left ear, which was blood tinged. He had a history of intermittent recurrent bilateral ear discharge for over 30 years. There has been associated difficulty in hearing but no vertigo or any neurological symptoms. He is a known hypertensive and diabetic on treatment for the same since 20 years. No history of weight loss.

Otological examination of left ear revealed purulent bloody fluid in the left external auditory canal, subtotal perforation with granulation tissue in the tympanic cavity (Figure 1), which bled easily when touched. Right ear showed subtotal perforation.

No cranial nerve deficits were evident and no nodes were palpable in the neck. There was no trismus. Pure tone audiometry shown bilateral profound sensorineural hearing loss. 


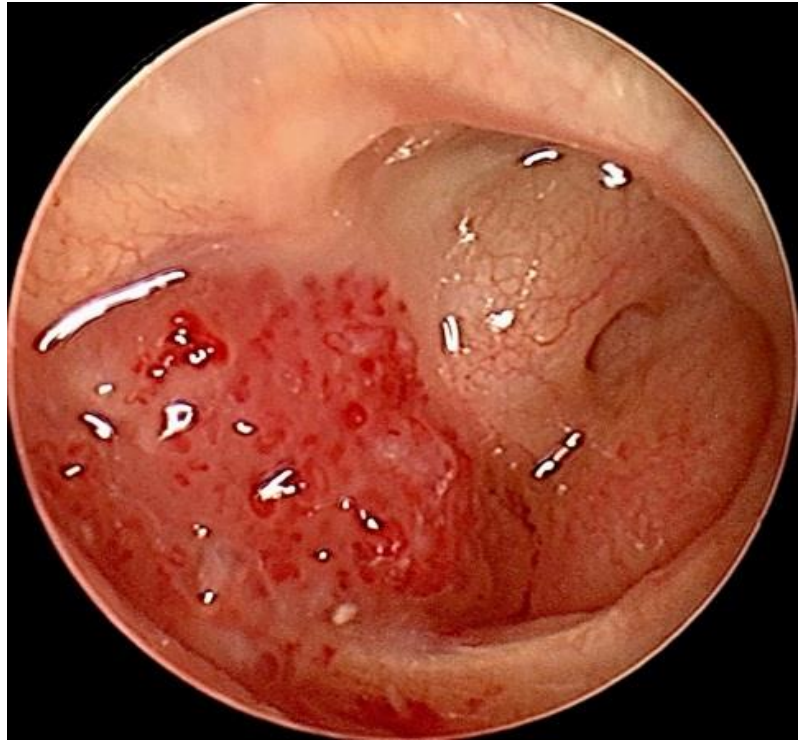

Figure 1: Left subtotal perforation with granulation tissue occupying anterior part of middle ear obstructing eustachian tube orifice.

High resolution CT scan with contrast of the temporal bone on the left side showed evidence of enhancing soft tissue lesion involving the middle ear - hypotympanum, mesotympanum, extending into eustachian tube orifice and epitympanum encasing the ossicles posteriorly soft tissue density lesion seen in mastoid antrum and aditus (Figure 2a-c).

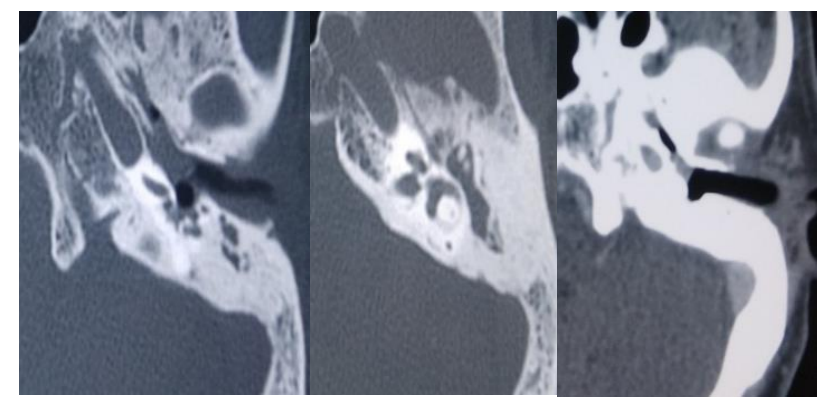

Figure 2: (a) soft tissue density lesion in middle ear obstructing eustachian tube orifice, (b) soft tissue density lesion occupying epitympanum and mastoid antrum, and (c) soft tissue density lesion in middle ear showing contrast enhancement.

Clinical diagnosis of bilateral CSOM with suspicion of associated tuberculosis or malignancy on left side was made. Biopsy from left ear performed under surface anesthesia, granulation tissue from the anteroinferior region of tympanic cavity taken and sent for histopathological examination, which revealed features suggestive of well differentiated squamous cell carcinoma (Figure 3).

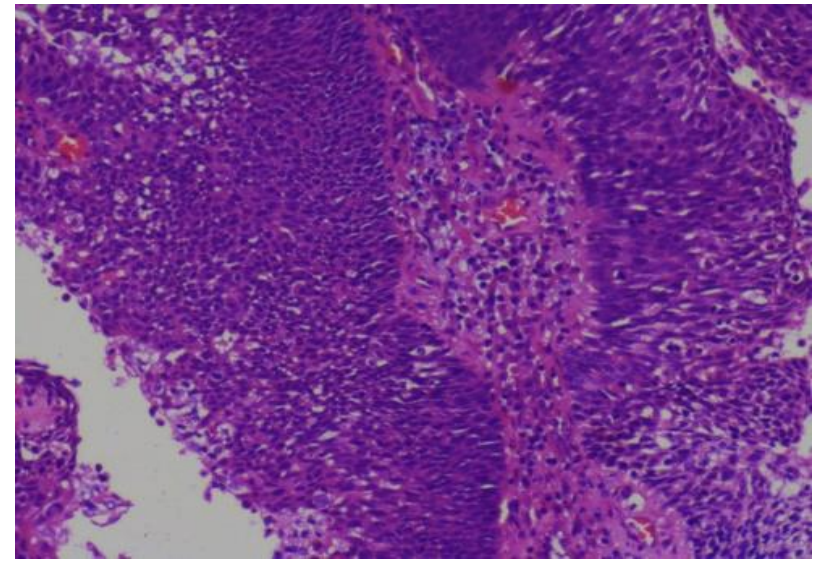

Figure 3: Left ear biopsy study showing well differentiated squamous cell carcinoma.

Patient managed by surgical intervention followed by radiation therapy. Radical clearance of the disease achieved. Antrum seen filled with fibrous granulation tissue which was suspicious of malignancy, hence cleared and sent separately for histopathological examination (HPE). Tumour mass in middle ear seen extending into eustachian tube orifice, excised in toto and sent for HPE in separate container. Granulation tissue seen extending from antrum into middle ear below the body of incus and head of malleus extending over facial canal up to stapes. For radical clearance malleus and inucs removed. Granulation tissue cleared in toto from antrum, epitympanum, over facial canal and around stapes including sinus tympani area. Middle ear mucosa scraped off completely. Ablation of underlying bone done with diode laser, in the antrum, over medial wall of middle ear in region of hypotympanum and tumor, and around eustachian tube orifice. Defect in attic due to removal of malleus and incus obliterated using auto conchal cartilage and double layer of crushed perisoteum. Histopathology revealed squamous cell carcinoma with minimal stromal invasion in section sent from tumor site (middle ear) (Figure 4). Another section sent from antrum didn't show any evidence of malignancy. Post operatively patient received radiation therapy after 6 weeks.

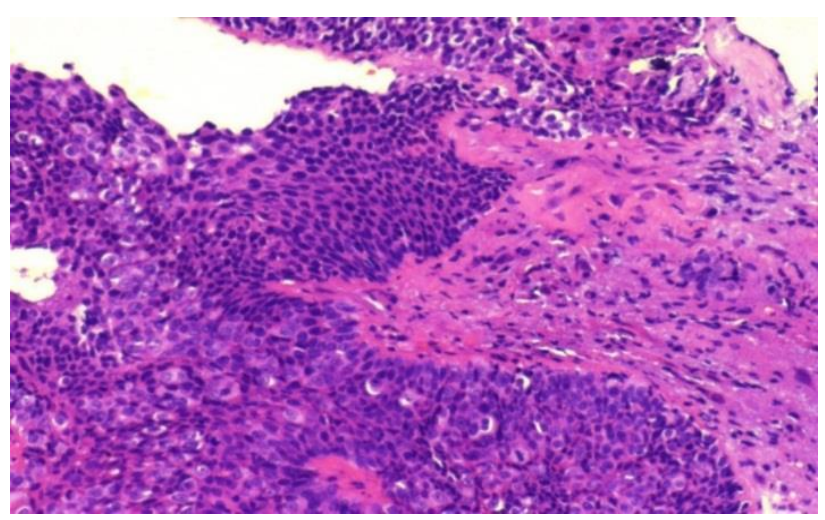

Figure 4: Left middle ear soft tissue histopathological study showing squamous cell carcinoma with minimal stromal invasion. 


\section{DISCUSSION}

Malignant tumors originating in the middle ear are rare. ${ }^{5}$ The etiological factors in primary middle ear carcinoma are unknown, but one possible cause is chronic otitis media. ${ }^{6}$

The classical hallmarks are otologic hemorrhage, intractable pain, sudden deafness, facial palsy and other symptoms of inner ear damage, which may not be evident in few cases. ${ }^{1}$ The common age group of presentation is between $5^{\text {th }}-6^{\text {th }}$ decade. However cases have been reported in children as young as 8 years. It is usually a unilateral disease however bilateral cases have been reported. Middle ear cancer masquerades CSOM for at least 6 months before its diagnosis. The pre-existing CSOM with or without cholesteatoma further delays the diagnosis and poses several diagnostic and therapeutic challenges. ${ }^{7}$

Chronic otitis media has been implicated as the main etiological factor in this tumour. Between $75-85 \%$ of primary middle ear carcinomas are secondary to chronic suppurative otitis media ${ }^{8}$ which may be due to metaplasia of the middle ear mucosa caused by chronic inflammation. Radiation is the other factor implicated. More recently Jin et $\mathrm{al}^{9}$ have shown that there is a high prevalence of human papilloma virus (HPV)-16/18, at both the tissue level and molecular level, of patients with middle ear squamous cell carcinoma. This might provide an insight into the role of chronic inflammation.

There are no clear-cut theories in the literature on the facilitation of the genesis of malignancy by CSOM or Cholesteatoma. Lodge et al. suggested that the chronic otitis might promote the development of a carcinoma in the middle ear in a manner analogous to the skin adjacent to draining sinuses resulting from chronic osteomyelitis. ${ }^{2}$

Middle ear SCC, though a rare entity should be considered with a high index of suspicion when there is refractory or excessively bleeding granulation. Histopathologic examination of all granules and polyps is of significance in early diagnosis and treatment. ${ }^{10} \mathrm{SCC}$ in the early stage is susceptible to be cured and in advanced stage, surgical resection with radiotherapy and chemotherapy could improve the survival. Recurrence and metastasis mainly occur in advanced stages and result in a poor survival. ${ }^{11}$.

\section{CONCLUSION}

This case is reported for the rare incidence of the occurrence of SCC in association with CSOM. Early identification of malignancy helps in preventing the progression of the disease, thereby initiating early treatment, and thus improving the survival rate.

Funding: No funding sources

Conflict of interest: None declared

Ethical approval: Not required

\section{REFERENCES}

1. Kumar KS, Venugopal M, Rajan S. Middle ear malignancy masquerading as csom. Indian J Otolaryngol Head Neck Surg. 2001;53:135-7.

2. Hu XD, Wu TT, Zhou SH. Squamous cell carcinoma of the middle ear: report of three cases. Int J Clin Exp Med. 2015;8(2):2979-84.

3. Agada FO, Gnananandha C, Wickham M. Squamous Cell Carcinoma of The Middle Ear: Case Report And Literature Review. Ann Afr Med. 2004;3(2):90-2

4. Davanageri SR, Bannur HB, Harugop AS, Pilli GS. Squamous cell carcinoma of the middle ear arising from CSOM: A case report. J Sci Soc. 2014;41:57-8.

5. Sinha PP, Aziz HI. Treatment of Carcinoma of the Middle Ear. Radiology. 1978;126(2):485-7.

6. Tsai ST, Li C, Jin YT, Chao WY, Su IJ. High prevaᄀlence of human papillomavirus types 16 and 18 in middle-ear carcinomas. Int $\mathbf{J}$ Cancer. 1997;71:208-12.

7. Deka RC. Middle-ear carcinoma in a girl of eighteen. J Laryngol Otol. 1980;94:429-31.

8. Zhang F, Sha Y. Computed tomography and magnetic resonance imaging findings for pri $\neg$ mary middle-ear carcinoma. J Laryngol Otol. 2013; $127: 578-83$.

9. Jin YT, Tsai ST, Li C. Prevalence of human papilloma virus in middle ear carcinoma associated with chronic otitis media. Am J Pathol. 1997; 150:1327-33.

10. Vikram BK, Saimanohar S, Narayanaswamy GN. Is Squamous Cell Carcinoma of Middle Ear a Complication of Chronic Suppurative Otitis Media? Internet J Otolaryngol. 2007;6:10.

11. Yin M, Ishikawa K, Honda K, Arakawa T, Harabuchi $\mathrm{Y}$, Nagabashi T, et al. Analysis of 95 cases of squamous cell carcinoma of external and middle ear. Auris Nasus Larynx. 2006;33:251-7.

Cite this article as: Mahajan $\mathrm{NH}$, Asha M, Vijayendra V, Honnurappa V. Middle ear squamous cell carcinoma - a case report. Int J Otorhinolaryngol Head Neck Surg 2021;7:1358-60. 